\title{
Nilai Nasionalisme Kebangsaan Aktivis Rohis
}

\author{
Ashif Az Zafi \\ Institut Agama Islam Negeri (IAIN) Kudus, Indonesia \\ ashifazzafi@iainkudus.ac.id \\ Ismail Suardi Wekke \\ Sekolah Tinggi Agama Islam Negeri (STAIN) Sorong, Indonesia \\ ismail@stain-sorong.ac.id
}

\begin{abstract}
Having a Nationalism Value is a part of daily life the citizen. In other words, it is an unconditional value. At the same time, the issue of racial disunity has been grown lately. This issue is related to religion. Most compelling evidence, high school student's Nationalism Value moreover theirs who follow spiritual organization has been descending due to the incorporation between religion and nationality. The scope of this field research is within SMA Negeri 1 Purworejo. Qualitative analysis method supported by descriptive statistical data is being used in this study. As a result, this research found that Nationalism Value can be instilled through classroom learning, recitation and activities in the spiritual program. The value of Unity and Patriotism, which constitutes for Nationalism Value, is invested through verbal and non verbal communication. For this reason, Islamic religion teacher is the most crucial agent in instilling Nationalism Values to spiritual activists. In the event that $57 \%$ of students have a high Unity Value and $68 \%$ of students have high Patriotism Value, henceforth the Nationalism's Value of spiritual activists tends to be high.
\end{abstract}

Keywords: Value, Nationalism, Rohis

\section{Abstrak}

Nilai Nasionalisme Kebangsaan merupakan bagian dari kehidupan seorang warga negara. Namun akhir-akhir ini marak isu yang berkaitan dengan perpecahan Bangsa. Isu tersebut berkaitan dengan agama. Salah satu isu agama dan kebangsaan adalah semakin terkikisnya Nilai Nasionalisme Kebangsaan dikalangan remaja SMA terutama yang mengikuti organisasi rohis. Penelitian ini merupakan penelitian lapangan yang dilakukan di SMA Negeri 1 Purworejo. Penelitian ini menggunakan analisis kualitatif yang didukung dengan data statistik deskriptif. Penelitian ini menemukan bahwa Nilai Nasionalisme Kebangsaan dapat ditanamkan melalui pembelajaran di kelas, pengajian dan kegiatan dalam program rohis. Nilai Kebangsaan yang tediri dari Nilai Persatuan dan Kesatuan serta Nilai Cinta Tanah Air ditanamkan melalui komunikasi verbal maupun non verbal. Agen yang paling berperan dalam menanamkan Nilai Nasionalisme Kebangsaan kepada aktivis rohis adalah Guru PAI. Nilai Nasionalisme Kebangsaan yang dimiliki aktivis rohis cenderung tinggi. Hal itu dibuktikan 
dengan 57\% siswa memiliki Nilai Persatuan dan Kesatuan yang tergolong tinggi serta 68\% siswa memiliki Nilai Cinta Tanah Air yang tergolong tinggi.

Kata kunci: Nilai, Nasionalisme, Rohis

\section{A. Pendahuluan}

Presiden RI Joko Widodo (Jokowi) meminta agar pelaku penyebar berita palsu alias hoax dan juga fitnah berbau agama harus ditindak tegas dan keras. Presiden Joko Widodo menggelar rapat terbatas membahas antisipasi terkait dengan media sosial. Rapat tersebut juga menyinggung mengenai MCA (Muslim Cyber Army). Dalam rapat itu, Jokowi meminta aparat hukum melakukan penindakan yang tegas dan keras bagi pengguna media sosial yang melontarkan ujaran kebencian dan fitnah.Jokowi sadar bahwa perkembangan teknologi memberikan dampak negatif bagi masyarakat. "Seperti yang kita lihat akhir-akhir ini, banyak berseliweran informasi yang meresahkan, mengadu-domba, memecahbelah," ujar Jokowi (Detik: 21 Maret 2018). Berita tersebut mengindikasikan bahwa saat ini banyak beredar informasi yang ingin memecah belah Indonesia. Hal ini sudah disadari oleh pmerintah.Berita yang disebar ingin melunturkan rasa persatuan dan kesatuan, mengadu-domba satu sama lain, memecah belah Bangsa Indonesia. Tidak sedikit berita yang mengaitkannya dengan isu-isu SARA terutama agama.

Organisasi Islam ikut memberikan komentar mengenai isu-isu agama yang bebau kebangsaan. Berdasarkan berita yang dirilis oleh Kompas (Kompas: Agustus 2017 sampai Januari 2018) setidaknya terdapat empat organisasi Islam yang muncul. Organisasi Islam yang memberikan komentar yaitu Nahdlatul Ulama, Muhammadiyah, Hizbut Tahrir Indonesia dan Majelis Ulama Indonesia. Komentar organisasi tersebut berkaitan dengan Nilai Kebangsaan. Selain organisasi yang berskala nasional, terdapat organisasi dilingkup persekolahan yang dianggap berkaitan dengan isu-isu keagamaan dan kebangsaan. Organisasi tersebut adalah Rohani Islam (Rohis) di sekolah.

Rohis di sekolah dapat memunculkan benih radikalisme di kalangan remaja. Pada tahun 2011, beberapa alumni dan aktivis rohis dari sebuah SMKN di 
Kabupaten Klaten Jawa Tengah ditangkap atas dugaan melakukan aksi terorisme di kabupaten tersebut (Hayadin, 2013: 231-240). Penelitian oleh MAARIF Institute menyimpulkan bahwa bibit gerakan radikalisme dapat tumbuh subur di sekolah karena pihak sekolah cenderung bersikap terbuka terhadap pihak-pihak luar. Pihak luar yang dimaksud pada umumnya adalah alumni dari sekolah tersebut yang telah berafiliasi dengan organisasi berpaham radikal. Selanjutnya, para alumni tersebut mencoba menginternalisasi ideologi radikal melalui kegiatan mentoring, liqo, dan atau halaqoh (Gaus, 2013: 174-191). Berdasarkan penelitian pada tahun 2013 yang dilakukan oleh ACDP Indonesia (Education Sector Analytical and Capacity Development Partnership) di beberapa wilayah Indonesia, Pendidikan Agama Islam di sekolah menengah menanamkan benih paham radikal. Benih paham radikal ini masuk secara langsung melalui partisipasi dalam organisasi masa yang berpaham radikal di masyarakat dan secara tidak langsung penggiatnya melakukan intervensi kegiatan ekstrakurikuler terutama rohis(Sari Soegondo, 2016: 2).

Terdapat juga penelitian serius mengenai rohis yang berkaitan dengan dakwah Islam modern. Studi mengenai rohis pada tahun 2011 dilakukan oleh Farid Wajidi, Hairus Salim HS dkk dan Najib Kailani. Penelitian Farid Wajidi menjelaskan bahwa fenomena rohis berkaitan erat dengan gerakan Islam pada masa Orde Baru dan Reformasi. Wajidi menjelaskan bahwa gerakan Islam kampus yang mencapai kematangannya pada masa Orde Baru meyebabkan gerakan ini mengembangkannya pada dunia politik dan sekolah-sekolah. Wajidi mengatakan bahwa dominasi gerakan keislaman rohis di sekolah mendiskriminasi ekspresi kebebasan yang lain sehingga memicu intoleransi di kalangan remaja (Farid Wajidi dkk, 2011: 89-113). Berbeda dengan temuan Wajidi, penelitian Hairus Salim, Najib Kailani dan Nikmal Azekiyah di Yogyakarta menunjukkan bahwa meskipun terdapat gejala intoleran akibat dominasi rohis namun siswa menegosiasikan bahkan meghadapkan identitas mereka dengan dominasi rohis. Terdapat dimensi "agency" siswa yang mempertanyakan bahkan menolak praktik keislaman rohis yang konservatif (Hairus Salim HS, 2011: 67-83). Penelitian lain yang dilakukan oleh Najib Kailani melihat sisi lain dari munculnya gerakan 
dakwah rohis. Najib Kailani menyebutkan bahwa keberadaan rohis tidak terlepas dari munculnya Budaya Pop Barat yang masuk ke Indonesia. Budaya Pop Barat direspon oleh gerakan dakwah Islam sehingga terbentuklah rohis di sekolah. Hal ini disebabkan oleh kekhawatiran terhadap Budaya Pop Barat yang akan menggerus moral remaja muslim (moral panics) (Najib Kailani, 2011: 89-107).

Hasil penelitian sebelumnya diperkuat dengan penelitian terbaru yang dilakukan oleh beberapa lembaga. Penelitian yang dilakukan pada tahun 2016 hingga 2017 berkaitan tentang disintegrasi Nilai Kebangsaan dalam organisasi rohis. Penelitian dilakukan oleh Masooda Bano dkk, Wahid Foundation dan Balitbang Kemenag Jateng. Studi Masooda Bano dkk dilakukan di beberapa daerah Indonesia utamanya di pulau Jawa. Studi ini menjelaskan ada radikalisme di Sekolah Menengah. Jalur utama masuknya radikalisme di sekolah melalui organisasi Rohis (Masoda Bano dkk, 2016: 4). Studi tersebut dikuatkan dengan hasil temuan dari Wahid Foundation yang melakukan penelitian pada kalangan aktivis Rohis yang melakukan Perkemahan Rohis Nasional di Cibubur tahun 2016. Studi ini menyimpulkan bahwa lebih dari $20 \%$ aktivis Rohis sering dan sangat sering mendengarkan pengajian yang bersifat radikal, 33\% mengartikan jihad sebagai perang, 78\% mendukung ide kekhalifahan dan relasi sosial aktivis Rohis cenderung terbuka (70\%) namun rendah dalam mengucapkan selamat hari raya pada umat beragama lain (66\%) (Wahid Foundation, 2016). Studi terbaru dilakukan Balitbang Kemenag Jateng yang melakukan penelitian di Purworejo, Surakarta dan Sleman. Studi ini menyimpulkan bahwa (1) Rohis setingkat SMA merupakan organisasi yang paling berperan dalam melakukan transmisi nilai keagamaan karena remaja usia SMA sebagai bentuk kaderisasi untuk membentuk militansi bermuara pada orientasi politik menguasai perlemen bahkan pemerintahan, (2) Orientasi politik angota Rohis terkait pemilihan pemimpin diutamakan adalah laki-laki yang beragama Islam, Rohis tidak anti demokrasi, pendukung NKRI lebih banyak dibanding pendukung khilafah, (3) Sikap toleransi anggota Rohis terbagi menjadi 2 tipe yaitu eksklusif dan inklusif, yang paling menonjol adalah tipe eksklusif terhadap umat yang berbeda dengan agama yang dipeluk anggota Rohis (Balitbang Agama Semarang, 2017). 
Kenyataan mengenai rohis bertentangan dengan hakekat Pendidikan Islam. Pendidikan Islam di sekolah pada dasarnya berusaha untuk membina sikap dan perilaku keberagaman peserta didik itu sendiri yang tidak hanya difokuskan pada aspek pemahaman (tentang agama) semata tetapi bagaimana usaha pendidikan agama (Islam) mampu menanamkan perilaku khalq dan khuluqnya, dengan mengetahui ajaran agama (knowing) kemudian mempraktekkan tentang apa yang diketahuinya (doing), dan mampu beragama atau menjalani hidup atas dasar ajaran dan nilai-nilai agama (being) (Muhaimin, 2009: 306). Pendidikan Islam memang merupakan suatu upaya pendidikan dan ajaran nilai-nilai Islam menjadi way of life seseorang. Namun demikian, sebagai pandangan dan sikap hidup, nilai-nilai tersebut akan bisa berimplikasi positif maupun negatif, sebab penanaman konsep nilai semacam itu berpotensi mewujudkan pada sikap integrasi atau disintegrasi, berpotensi mengarah pada sikap toleran atau intoleran yang dapat merusak persatuan bangsa. Fenomena-fenomena tersebut tidak menutup kemungkinan akan banyak ditentukan setidaknya oleh pandangan teologi agama dan doktrin ajarannya; sikap dan perilaku pemeluknya dalam memahami dan menghayati agama tersebut; lingkungan sosio-kultur yang mengelilinginya; dan peranan dan pengaruh pemuka agama termasuk guru agama dalam mengarahkan pengikutnya (Faisal Ismail, 2014: 46).

Pada dasarnya semua agama membawa misi untuk menciptakan kedamaian dan mempererat solidaritas dalam kehidupan berbangsa dan bernegara. Tetapi dalam waktu bersamaan, agama juga bisa menimbulkan konflik sosial. Karena itu, nilai Nasionalisme Kebangsaan perlu diajarkan melalui Pendidikan Islam. Ada radikalisme di dalam beragama yang harus dinetralisasi oleh Pendidikan Islam. Sebenarnya bukan agama yang mengajarkan kekerasan, tetapi orang yang menerjemahkan agama itu berpandangan radikal (Balitbang Agama Semarang, 2016). Dalam hal ini, sebagai manusia beriman, guru agama punya tanggungjawab untuk mewujudkan kedamaian di keluarga, sekolah dan masyarakat.

Tujuan Pendidikan Agama dalam Peraturan Menteri Agama No. 16 Tahun 2010 mengamanatkan kepada sekolah untuk melaksanakan Pendidikan Agama. 
Dalam pasal 6 dijelaskan bahwa Pendidikan Agama bertujuan untuk mewujudkan kerukunan antar umat dalam membangun persatuan dan kesatuan bangsa. Proses pembelajaran pendidikan agama dapat dilakukan melalui kegiatan intrakulikuler dan ekstrakurikuler (PMA No. 16, 2010). Salah satu kegiatan ekstrakurikuler pendidikan agama di sekolah adalah Rohis. Maka dari itu Rohis diharapkan mampu menanamkan Nilai Nasionalisme Kebangsaan.Secara eksplisit disebutkan dalam UUD 1945 pasal 31 ayat 3 bahwa pendidikan di Indonesia bertujuan untuk meningkatkan keimanan dan ketakwaan serta akhlak mulia. Dalam konteks kebangsaan, hal tersebut dapat dimaknai sebagai manusia yang memiliki wawasan dan kepribadian Pancasila, yaitu manusia yang religius, berwatak kerakyatan, berkeadilan sosial, menjaga persatuan tanpa melalui kekerasan.Oleh karena itu, wawasan nasionalPancasila perlu dikembangkan dalam Rohis sehingga dapat menjadi jembatan kepentingan agama dan kepentingan bangsa dalam konteks relasi-relasi sosial (Ridwan, 2012: 173-196).

Gerakan Islam radikal yang semakin berkembang pada rohis serta menyasar kaum muda sebenarnya bisa ditangkal dengan pemahaman kebangsaan yang komprehensif. Pemahaman kebangsaan yang dimaksud adalah pemahaman akan pentingnya persatuan dan kesatuan bangsa berlandaskan Pancasila, UUD 1945, Bhinneka Tunggal Ika, serta Negara Kesatuan Republik Indonesia. Pancasila sebagai sumber hukum di Indonesia tidak perlu dipertentangkan dengan ajaran Agama Islam karena pencetus Pancasila mengadopsi teks ajaran Agama Islam menjadi sila-sila Pancasila (Khamdan, 2016: 207-232). Namun demikian, hal inilah yang tidak dipahami oleh gerakan Islam radikal yang menuntut penetapan hukum Islam secara mutlak di Indonesia.

Penelitian ini bertujuan untuk mengetahui cara menanamkan Nilai Nasionalisme Kebangsaan dan tingkat Nilai Nasionalisme Kebangsaan yang telah tertanam. pada aktivis Rohis di SMA Negeri 1 Purworejo. Pemilihan tempat penelitian karena terdapat berita yang mengabarkan bahwa $70 \%$ siswa di Purworejo menganut paham radikal (Sorot Purworejo, 29 Mei 2017) dan ada stigma dari masyarakat bahwa Rohis SMA Negeri 1 Purworejo merupakan Rohis yang berpaham radikal. Namun SMA Negeri 1 Purworejo juga merupakan 
sekolah rujukan yang menerapkan Wawasan Kebangsaan (Padmo Sukoco, Kepala SMA N 1 Purworejo, 10 Januari 2018).

\section{B. Pembahasan}

\section{Rohis dan Nasionalisme Kebangsaan}

Rohani Islam atau biasa disebut dengan rohis merupakan salah satu organisasi kesiswaan yang berada di lingkungan sekolah. Rohis merupakan organisasi yang berlandaskan konsep nilai keislaman dan menjadi sarana memperdalam pemahaman Agama Islam para anggotanya. Posisi rohis di sekolah dapat dikatakan sebagai wadah keagamaan yang bersifat independen karena dikembangkan secara mandiri oleh siswa serta pembina rohis (Noer dkk, 2017: 21-38). Sebagaimana organisasi kesiswaan lainnya, rohis juga memiliki struktur organisasi, seperti ketua, wakil ketua, bendahara, sekretaris, dan divisi-divisi yang bertugas pada bagiannya masing-masing (Imania, 2012: 32).

Kegiatan Rohis bertujuan untuk mewujudkan generasi muda yang kuat, bertakwa, sekaligus cerdas, memiliki kesamaan cara pandang, visi, dan akidah, sehingga memiliki peribadatan yang sama, tujuan yang sama, serta harmoni dalam gerak langkahnya menyerupai barisan yang kokoh. Barisan ini harus pandai memadukan aspek iman dan takwa (imtak) serta ilmu pengetahuan dan teknologi (iptek). Kecerdasan, kemampuan intelektual, ketekunan belajar dan berlatih, serta kedisiplinan adalah bekal dasar agar dapat menjadi manusia yang kompetetif dalam menghadapi masa depan di era globalisasi (Imania, 2012: 35).

Kerohanian Islam memiliki dua fungsi utama yaitu syakhsiyah islamiyyah, yaitu pribadi-pribadi yang Islami. Maksudnya adalah rohis berfungsi membina muslim teladan yang menjadi pribadi-pribadi yang unggul, baik dalam kapasitas keilmuannya maupun keimanannya. Fungsi lainnya adalah untuk pembentukan jama'atul muslimin. Hal ini bermakna rohis berfungsi sebagai 'base camp' dari siswa-siswi muslim, untuk menjadikan pribadi maupun komunitas yang Islami. Dari sini maka tekad untuk membumikan Islam akan mudah tercapai (Imania, 2012: 34). Melalui dua fungsi utamanya, rohis berperan penting dalam pembinaan agama Islam di lingkungan sekolah. Fungsi rohis tersebut terdapat dalam Visi rohis di setiap sekolah. Rohis SMA Negeri 1 Purworejo memiliki visi 
yaitu"Memperkuat ukhuwwah Islamiyah dan ukhuwah insaniyah dengan membumikan Islam Rahatallil'alamin”. Visi Kerohanian Islam (Rohis) bertujuan untuk mewujudkan barisan pelajar yang mendukung dan memelopori persaudaraan sesama dan antar umat beragama. Tujuannya agar pelajar muslim mempunyai nilai dan mampu bersikap damai terhadap sesama (Faqih, Ketua rohis SMAN 1 Purworejo, 11 Januari 2018). Berdasarkan visi rohis SMA Negeri 1 Purworejo, terdapat nilai Nasionalisme Kebangsaan yang ingin ditanamkan kepada aktivis Rohis. Nasionalisme mengacu kepada kesadaran warga negara akan pentingnya persatuan bangsa dan dalam visi rohis SMA Negeri 1 Purworejo mengedepankan ukhuwah baik islamiyah maupun insaniyah. Para pendiri bangsa tidak menjadikan agama sebagai sumber hukum negara karena Negara Indonesia memiliki keragaman dalam hal agama, suku, bangsa, bahkan status sosial. Oleh karena itu, Pancasila dengan semboyan "Bhinneka Tunggal Ika" diputuskan sebagai dasar negara dan sumber dari segala hukum yang ada di Indonesia. Semboyan tersebut merupakan penegasan bahwa perbedaan yang ada di Indonesia merupakan sumber kekuatan untuk menciptakan persatuan dan kesatuan bangsa (Khamdan, 2016: 217).

Semangat kebhinnekaan tersebut juga melandasi munculnya wawasan kebangsaan yang tercermin dalam setiap sila dalam Pancasila. Sebagaimana yang dijelaskan oleh Sugiyarto (Sugiyarto, 2012: 1-8), sila pertama bermakna pentingnya keimanan dan ketakwaan diperlukan sebagai unsur pemersatu, sila kedua bermakna pengamalan kewajiban dan hak asasi manusia sehingga perilaku yang ditampilkan dalam kehidupan bernegara tidak melanggar hak-hak asasi orang lain, sila ketiga dapat dikatakan penggambaran eksplisit wawasan kebangsaan dimana interaksi semua elemen bangsa ditujukan untuk menciptakan persatuan dan kesatuan, sila keempat bermakna kepentingan rakyat merupakan yang paling utama yang tercermin dalam demokrasi Pancasila, dan sila kelima menunjukkan bahwa keadilan diperuntukkan bagi seluruh masyarakat tanpa melihat perbedaan yang ada.

Pemahaman kebangsaan yang komprehensif mutlak diperlukan dalam menangkal gelombang radikalisme yang mulai menginfiltrasi dunia pendidikan di 
Indonesia. Darraz (Darraz, 2013: 154-173) menyatakan bahwa materi pelajaran untuk pendidikan kewarganegaraan dan pendidikan Agama Islam belum mencerminkan karakter dan nilai kebangsaan secara operasional. Inilah sebab pembentukan karakter siswa sebagai warga negara yang baik di tengah realitas keragaman belum terwujud.

\section{Nilai Nasionalisme Kebangsaan Aktivis Rohis}

Menurut Richard West dan Lynn H. Turner (Richard, 2010: 5), komunikasi adalah "A social process in which individuals employ symbols to establish and interpret meaning in their environment". Berdasarkan pengertian tersebut bahwa komunikasi merupakan proses sosial untuk memahami makna di lingkungan dimana manusia tersebut tinggal. Nilai Nasionalisme Kebangsaan dapat diketahui dengan memahami makna lingkungan sekolah dimana aktivis rohis melakukan proses soseial. Menurut Onong Uchjana Effendy (Effendy, 2005: 11), komunikasi mengalami beberapa tahapan yang disebut sebagai proses komunikasi. Proses komunikasi terdiri dari komunikator, pesan, media dan komunikan. Dimana komunikator menyampaikan pesan (nilai) sesuai tujuan yang diharapkan kepada komunikan melalui media tertentu. Pemahaman komunikan mengenai pesan dapat diketahui berdasarkan feedback yang diberikan. Komunikasi akan menjelaskan melalui jalur apa Nilai Nasionalisme Kebangsaan masuk, apa pesan (Nilai Nasionalisme Kebangsaan) yang ditransmisikan kepada aktivis rohis dan bagaimana Nilai Nasionalisme Kebangsaan yang terdapat pada komunikan (aktivis rohis).

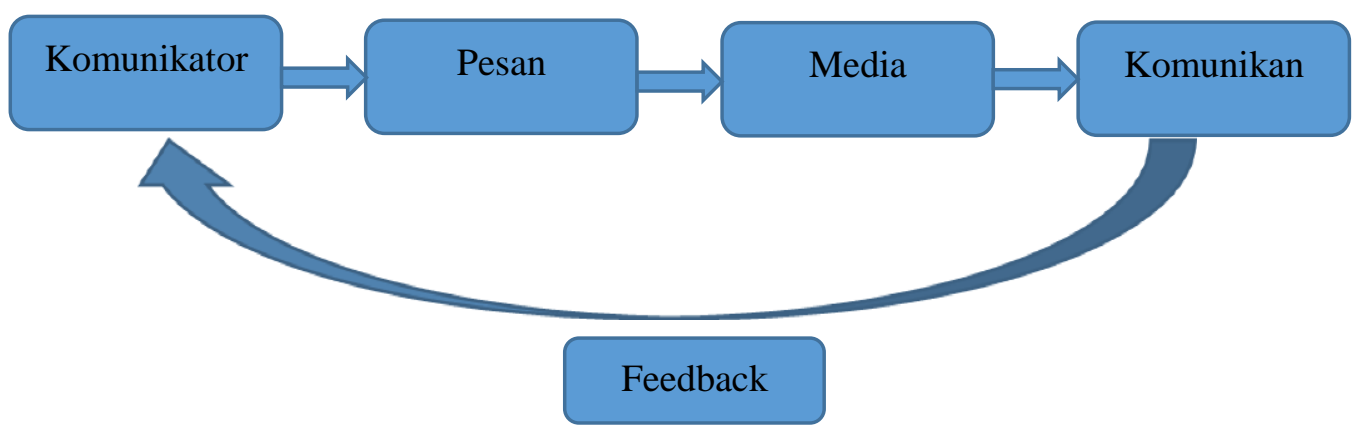

Gambar 1. Proses Komunikasi 
Komunikator adalah pihak yang bertindak sebagai pengirim pesan dalam proses komunikasi. Dengan kata lain, komunikator merupakan seseorang atau sekelompok orang yang berinisiatif untuk menjadi sumber dalam sebuah hubungan. Komunikator tidak hanya berperan sebagai pengirim pesan saja, namun juga memberikan respons dan menjawab pertanyaan yang disampaikan sebagai dampak dari proses komunikasi yang berlangsung, baik secara langsung maupun tidak langsung (Effendy, 2005: 12).

Berdasarkan hasil temuan dan analisis menunjukkan bahwa komunikator memegang peran sentral dalam penanaman Nilai Nasionalisme Kebangsaan kepada komunikan (aktivis rohis). Komunikator merupakan tokoh sentral sebagai tempat bergantung dan tempat bertanya peserta didik. Ada beberapa komunikator proses penanaman Nilai Nasionalisme Kebangsaan dalam organisasi rohis yaitu Guru PAI, penceramah dan sesama siswa. Peran utama adalah Guru PAI.

SMA Negeri 1 Purworejo mempunyai tiga Guru PAI. Pertama, Herman Suwardi berpendidikan S2 dari IAIN Syarif Hidayatullah Jakarta. Beliau memiliki latar belakang ilmu al Quran yang kuat. Dalam pembelajaran menekankan pada bacaan al Quran yang tartil dan benar. Beliau menekankanNilai Nasionalisme Kebangsaan dalam kegiatan Peringatan Hari Besar Islam (Maulid Nabi dan Isra'Mi'raj). Namun beliau kurang setuju dengan pemimpin non muslim. Beliau berafiliasi dengan organisasi Nahdlatul Ulama. Kedua, Titik Istiqomah berpendidikan S1 dari IAIN Salatiga. Beliau lebih menekankan pada pembelajaran yang praktis dan mengkontekstualisasikan dengan masalah aktual. Beliau berafiliasi dengan organisasi Nahdlatul Ulama. Ketiga, Ahmad Faizin berpendidikan S1 dari IAIN Walisongo Semarang. Beliau memiliki background pesantren yang kuat. Dalam pembelajaran Beliau lebih menekankan pada pembelajaran yang praktis sesuai dengan Kompetensi Dasar. Dalam kegiatan diluar pembelajaran (yang masih berkaitan dengan program keislaman sekolah) beliau lebih menkankan pada penangkalan bibit radikalisme dan liberalisme. Beliau berafiliasi dengan organisasi Nahdlatul Ulama (Herman, Guru PAI SMAN 1 Purworejo, 10 Januari 2018). 
Penentuan penceramah kegiatan di sekolah merupakan pilihan siswa yang dikonsultasikan dengan Pembina. Penceramah di SMA Negeri 1 Purworejo ada yang dari daerah Purworejo dan luar daerah. Penceramah didatangkan ketika ada acara PHBI atau kegiatan seperti MABIT dan KISS (Kajian Islam Sepulang Sekolah). Penceramah yang sering mengisi adalah Bapak K.H. Abdul Haq yang memiliki background pesantren Nahdlatul Ulama yang memberikan pengajuan tentang rasa toleransi dan nasionalisme. Ada juga Kyai dari Kebumen yang memiliki background Nahdlatul Ulama. Ada juga Kyai yang merangkap sebagai dosen di UNSIQ Wonosobo. Ada juga kegiatan shalat jumah yang di isi oleh khatib dari kalangan Guru PAI di SMA Negeri 1 Purworejo (Sekar, Sekertaris rohis SMAN 1 Purworejo, 11 Januari 2018).

Siswa dapat menjadi komunikator dalam mentransfer Nilai Nasionalisme Kebangsaan. Aktivisrohis melakukan transfer nilai dengan menggunakan media sosial dan artikel 2 bulanan. Latar belakang siswa yang mengikuti rohis berasal dari pesantren, ormas Nahdlatul Ulama, ormas Muhammadiyah dan ormas HTI (Faqih, Ketua rohis SMAN 1 Purworejo, 11 Januari 2018). Untuk tahun 2017/2018 yang menjadi Pengurus Harian merupakan siswa yang memiliki background pesantren Nahdlatul Ulama.

Pesan merupakan keseluruhan apa yang disampaikan oleh komunikator. Pesan dapat berupa kata-kata, tulisan, gambaran atau perantara lain. Pesan ini memiliki inti, yakni mengarah pada usaha untuk mengubah sikap dan tingkah laku komunikan. Inti pesan akan selalu mengarah pada tujuan akhir komunikasi itu (Effendy, 2005: 12). Pesan yang ditransfer merupakan Nilai Nasionalisme Kebangsaan. Nilai Nasionalisme Kebangsaan yang ditanamkan adalah persatuan dan kesatuan serta cinta tanah air. Pesan ini ditransfer melalui proses verbal dan non verbal (Agus, 2003: 22). Proses verbal dapat melalui pembelajaran dan program sekolah sedangkan non verbal dapat berupa kegiatan.

Nilai Persatuan dan Kesatuan dilaksanakan melalui cara verbal. Menurut Mulyana (Mulyana, 2017: 28) komunikasi verbal merupakan komunikasi yang dilakukan dengan menggunakan bahasa. Bahasa merupakan simbol-simbol yang memiliki arti tertentu. Komunikasi verbal dapat dilakukan secara lisan atau 
tulisan. Guru PAI di SMA Negeri 1 Purworejo menyampaiakn prinsip-prinsip Persatuan dan Kesatuan pada penyampaian materi: (1) prasangka baik/husnuzan (kelas 10), (2) toleransi (kelas 11), (3) makna iman kepada kitab-kitab Allah SWT (kelas 11), (4) makna iman kepada rasul-rasul Allah SWT (kelas 11), (5) perkembangan Islam pada masa modern (kelas 11), (6) prinsip-prinsip dan praktek ekonomi dalam Islam (kelas 11), (6) strategi dakwah dan perkembangan Islam di Indonesia (kelas 12), (7) perkembangan dan kemunduran Islam di Indonesia (kelas 12).PeyampaianNilai Persatuan dan Kesatuan melalaui program rohis meliputi materi Sirah Nabi dan sahabat, adab bergaul dengan sesama, hubungan negara dengan Islam, kajian tentang Islam Rahmatan Lil Alamin dan pergaulan bebas.

Nilai Persatuan dan Kesatuan dilaksanakan melalui cara non verbal. Menurut Mulyana (Mulyana, 2007: 30) komunikasi non verbal merupakan komunikasi yang tidak menggunakan kata-kata dan tulisan. Komunikasi dilakukan dengan kegiatan atau gerak tubuh. Kegiatan yang dilakukan dalam menanamkan Nilai Persatuan dan Kesatuan adalah melalui penyembelihan hewan kurban yang dilaksanakan bersama-sama. Pengelolaan hewan kurban dilaksanakan oleh perwakilan kelas yang terdiri dari beberapa penganut agama. Dalam melaksanakan pengolahan hewan kurban tidak terjadi perbedaan antara penganut agama Islam dengan penganut agama lain. Begitupun dalam pembagian hewan kurban. Semua penganut agama mendapatkan bagian masing-masing. Selanjutnya ada kegiatan PIK R. Acara ini merupakan acara dari salah satu kepengurusan OSIS yang dibina oleh Guru Bimbingan Konseling. Pada tahun 2018, acara ini membahas mengenai pergaulan bebas dan zina. Acara ini diikuti oleh semua siswa kelas X. Pembicara dalam acara ini adalah Kyai, Pendeta dan Dinas Sosial.

Nilai Cinta Tanah Air dilaksanakan melalui cara verbal. Guru PAI di SMA Negeri 1 Purworejo menyampaiakn prinsip-prinsip Cinta Tanah Airpada penyampaian materi: (1) berprasangka baik, (2) metode dakwah Rasul di Mekkah (kelas 10), (3) metode dakwah Rasul di Madinah (kelas 10), dan (4) berpikir kritis dan demokratis (kelas 12). Penyampaian Nilai Cinta Tanah Air melalui program 
rohis meliputi materi Sirah Nabi dan sahabat, birul walidain, hubungan negara dengan Islam, kajian tentang wanita dalam Islam.

Nilai Cinta Tanah Air dilaksanakan melalui cara non verbal. Kegiatan yang dilakukan dalam menanamkan Nilai Cinta Tanah Air adalah melalui pemilihan ketua OSIS. Penentuan ketua OSIS dilaksanakan secara demokratis dengan cara pemilihan langsung. Semua siswa berhak mencalonkan diri (sesuai dengan peraturan). Semua siswa berhak memberikan hak suaranya dalam pemilihan ketua OSIS. Namun yang menjadi menarik bahwa ada beberapa siswa baik laki-laki ataupun perempuan yang menganggap bahwa ketua OSIS sebaiknya laki-laki. Namun tidak ada anggapan bahwa ketua OSIS harus bergama atau bersuku tertentu. Selain itu, Nilai Cinta Tanah Air juga ditampilkan dalam penentuan perwakilan kelas atau sekolah yang akan mengikuti lomba. Semua siswa berhak untuk mengikuti seleksi dalam setiap kegiatan. Semua siswa berhak mengembangkan dirinya dan mewakili kelas atau sekolah.

Media digunakan sebagai penyalur pesan dalam proses komunikasi. Pemilihan sarana/media dalam proses komunikasi tergantung pada sifat berita yang akan disampaikan (Cangara, 2012: 89).Media atau sarana yang digunakan mentransfer Nilai Nasionalisme Kebangsaan adalah program sekolah seperti PHBI, KISS, MABIT dan PIK R. Guru dan siswa juga menggunakan video atau youtube dalam pembelajaran. Media sosial yang digunakan seperti Facebook, Whatsapp, Instragram, Twitter. Media sosial ini digunakan oleh rohis dalam menanamkan Nilai Nasionalisme Kebangsaan. Selain media sosial pengurus rohis juga menggunakan artikel setiap 2 bulan sekali yang memuat kolom nasionalisme.

Komunikan merupakan penerima pesan atau berita yang disampaikan oleh komunikator. Komunikan bisa terdiri satu orang atau lebih, bisa dalam bentuk kelompok. Dalam proses komunikasi, komunikan adalah elemen penting karena dialah yang menjadi sasaran komunikasi dan bertanggung jawab untuk dapat mengerti pesan yang disampaikan dengan baik (Effendy, 2005: 13). Komunikan dapat dibagi menjadi 3 jenjang yaitu siswa kelas X, siswa kelas XI dan siswa kelas XII. 
Hasil penelitian menunjukkan bahwa Nilai Nasionalisme Kebangsaan tertanam dengan baik. Nilai Nasionalisme Kebangsaan terdiri dari Nilai Persatuan dan Kesatuan serta Nilai Cinta Tanah Air. Penilitian ini melihat Nilai Persatuan dan Kesatuan dari 20 aspek atau indikator yaitumembangun rasa persaudaraan, solidaritas, kedamaian, dan antikekerasan antarkelompok masyarakat dengan semangat persatuan; menjaga dan melindungi negara dari segala bentuk ancaman, baik dari dalam maupun luar negeri; memajukan pergaulan demi kesatuan dan persatuan bangsa; mengakui dan menghargai keanekaragaman pada diri bangsa Indonesia; ikut berpastisipasi dalam suatu kegiatan yang berguna untuk memajukan bangsa dan negara; mengembangkan persatuan Indonesia atas dasar Bhinneka Tunggal Ika; memiliki rasa senasib dan sepenanggungan diantara sesama bangsa Indonesia; ikut berpartisipasi dalam memelihara ketertiban bangsa dan negara; mampu menempatkan persatuan, kesatuan, serta kepentingan dan keselamatan bangsa dan negara sebagai kepentingan bersama diatas kepentingan pribadi dan golongan; menjungjung tinggi nilai-nilai persatuan dan kesatuan bangsa; menciptakan suasana aman, damai, dan tentram dalam kehidupan berbangsa dan bernegara; menjaga kedaulatan bangsa dan negara; aktif memberi usul, saran, dan kritik terhadap penyelenggara negara; menjaga ketertiban masyarakat dengan mematuhi aturan yang berlaku; mampu memperoleh prestasi pada kompetisi Internasional guna mengharumkan nama Negara; menjaga kerukunan antar sesama warga negara Indonesia; menciptakan suatu karya seni yang berhubungan dengan nasionalisme; mengembangkan nilai-nilai perjuangan bangsa yang dilandasi oleh jiwa tekad, dan semangat kebangsaan; mampu menunjukan identitas nasional dan kepribadian bangsa Indonesia; mengembangkan sikap hormat menghormati dan bekerja sama antar sesama bangsa Indonesia (Kartawinata, 1999: 98).

Penelitian ini melihat Nilai Cinta Tanah Air dari 20 aspek atau indikator yaitumengembangkan rasa cinta kepada tanah air dan bangsa; mengembangkan rasa kebanggaan berkebangsaan dan bertanah air Indonesia; memperingati dan menghayati hari kemerdekaan Negara Kesatuan Republik Indonesia; mencintai dan menggunakan produk dalam negeri; mematuhi dan mentaati peraturan negara; 
berinisiatif mengadakan perubahan demi kemajuan bangsa dan negara; menyaring masuknya budaya luar yang tidak sesuai dengan kepribadian bangsa; menanamkan rasa cinta tanah air sejak usia dini; mendukung tim-tim dari Indonesia pada saat berkompetisi di kancah Internasional; bangga menjadi bangsa Indonesia; menggunakan bahasa Indonesia yang baik dan benar; menjaga nama baik bangsa dan negara; belajar dengan sungguh-sungguh demi kemajuan bangsa dan Negara; mematuhi dan menghayati nilai-nilai yang ada pada UUD 1945 dan Pancasila; mengembangkan sikap kesetiaan kepada bangsa dan negara; bersedia mempertahankan dan memajukan negara; peduli terhadap segala bentuk masalah yang dihadapi dalam kehidupan berbangsa dan bernegara; ikut serta dalam upaya pembelaan negara; sanggup dan rela berkorban untuk kepentingan bangsa dan negara apabila diperlukan; bertindak secara teratur, menyeluruh, terpadu, dan berlanjut yang dilandasi oleh kecintaan pada tanah air (Kartodirdjo, 1999: 74).

Nilai Nasionalisme Kebangsaan diketahui dengan menggunakan angket berskala likert (Sugiyono, 2012: 93). Instrument skala likert, setelah melalui uji reliabilitas dan validitasnya, angket yang valid dan reliabel untuk sikap karakteristik Nilai Persatuan dan Kesatuan 30 item dan untuk sikap karakteristik Nilai Cinta Tanah Air 24 item. Skala sikap tersebut terdiri dari lima pilihan bertingkat, masing-masing item diberi skor satu sampai dengan lima, diberikan kepada 67 aktivis rohis SMA Negeri 1 Purworejo dan yang memenuhi syarat analisis ada 53 siswa. Perhitungan skala sikap Nilai Persatuan dan Kesatuan skor minimal 30, skor maksinal 150. Skala sikap Nilai Cinta Tanah Air skor minimal 24, skor maksimal 120. Perolehan masing-masing aspek tersebut dibagi ke dalam tiga tingkatan dengan jumlah interval sama dalam tiap tingkat. Selanjutnya diperoleh gambaran siswa dengan sikap Nilai Persatuan dan Kesatuan kurang, sedang dan tinggi serta sikap Nilai Cinta Tanah Air kurang, sedang dan tinggi. Hasil penelitian sikap Nilai Persatuan dan Kesatuan serta sikap Nilai Cinta Tanah Air aktivis rohis dapat ditampilkan pada grafik 1 dan 2. 


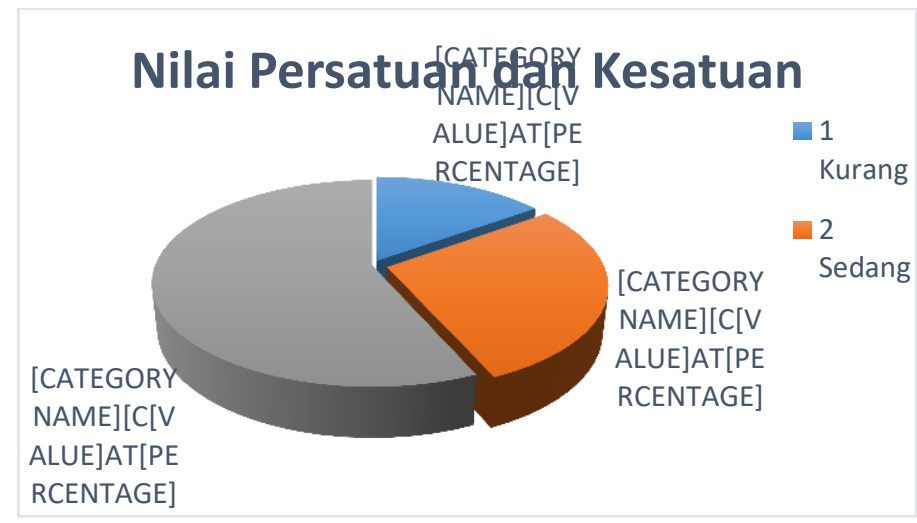

Grafik 1. Hasil Pengukuran Nilai Persatuan dan Kesatuan Aktivis Rohis

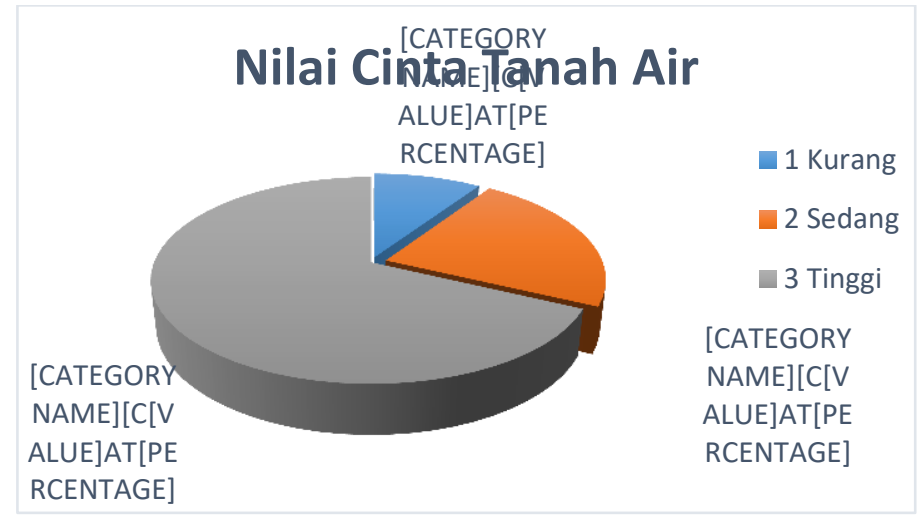

Grafik 2. Hasil Pengukuran Nilai Cinta Tanah Air Aktivis Rohis

Grafik 1 tentang Nilai Persatuan dan Kesatuan menunjukkan bahwa 8 siswa atau $15 \%$ aktivis rohis memiliki Nilai Persatuan dan Kesatuan yang kurang, 15 siswa atau 28\% aktivis rohis memiliki Nilai Persatuan dan Kesatuan yang sedang serta 30 siswa atau 57\% aktivis rohis memiliki Nilai Persatuan dan Kesatuan yang tinggi. Grafik 2 tentang Nilai Cinta Tanah Air menunjukkan bahwa 5 siswa atau 9\% aktivis rohis memiliki Nilai Cinta Tanah Air yang kurang, 12 siswa atau 23\% aktivis rohis memiliki Nilai Cinta Tanah Air yang sedang serta 36 siswa atau 68\% aktivis rohis memiliki Nilai Cinta Tanah Air yang tinggi. Berdasarkan data tersebut maka dapat disimpulkan bahwa Nilai Nasionalisme Kebangsaan yang dimiliki oleh mayoritas aktivis rohis SMA Negeri 1 Purworejo tergolong sedang bahkan tinggi.

\section{Kesimpulan}


Nilai Nasionalisme Kebangsaan merupakan nilai penting yang harus dimiliki oleh semua warga negara. Namun nilai ini semakin terkikis karena banyak faktor. Salah satunya berkembangnya paham keagamaan yang radikal. Paham ini masuk sekolah menengah melalui organisasi rohis. Namun tidak semua aktivis rohis memiliki Nilai Nasionalisme Kebangsaan yang rendah karena nilai tersebut juga dipengaruhi oleh budaya sekolah.

Penelitian ini menemukan bahwa Nilai Nasionalisme Kebangsaan dapat ditanamkan melalui pembelajaran di kelas, pengajian dan kegiatan dalam program rohis. Nilai Kebangsaan yang tediri dari Nilai Persatuan dan Kesatuan serta Nilai Cinta Tanah Air ditanamkan melalui komunikasi verbal maupun non verbal. Agen yang paling berperan dalam menanamkan Nilai Nasionalisme Kebangsaan kepada aktivis rohis adalah Guru PAI. Nilai Nasionalisme Kebangsaan yang dimiliki aktivis rohis cenderung tinggi. Hal itu dibuktikan dengan 57\% siswa memiliki Nilai Persatuan dan Kesatuan yang tergolong tinggi serta 68\% siswa memiliki Nilai Cinta Tanah Air yang tergolong tinggi. 


\section{DAFTAR PUSTAKA}

Ansori, Muhamad. 2017. Paham Radikalisme Sudah Racuni Pelajar, Pemerintah Didesak Agar Segera Turun Tangan. Sorot Purowrejo. Purowrejo.

Azra, Azyumardi, dkk. 2015. Pengayaan Muatan Nilai-nialai Budaya Damai dalam Materi Kurikulum Pendidikan Agama Islam dan Budi Pekerti di Sekolah Menengah (Buku Panduan Bagi Guru). Jakarta: Kementerian Agama Republik Indonesia.

Baidhawy, Zakiyudin. 2005. Pendidikan Islam Berwawasan Multikultural.Jakarta: Erlangga.

Balai Penelitian dan Pengembangan Agama Semarang. 2017. Transmisi Nilai-nilai Keagamaan Melalui Organisasi ROHIS (Orientasi Politik dan Sikap Toleransi Peserta Didik). Semarang.

Bano, Masooda, dkk. 2016. Study on Islamic Religious Education in Secondary Schools in Indonesia. Jakarta: Directorate General of Islamic Education.

Centre for Research and Development of Religious Education and Education, Board of Research, Development and Training. 2012.The Strategic Role of Religious Education in The Development of Culture of Peace.Bogor: Ministry of Religious Affair.

Cangara, Hafied. 2012. Pengantar Ilmu Komunikasi. Jakarta: Raja Grafindo Persada.

Darraz, M. A. 2013. Radikalisme dan Lemahnya Peran Pendidikan Kewargaan. Jakarta: MA'ARIF.

Detik. 2018. Berita Hoax Bisa Ancam Persatuan Dan Kesatuan Bangsa. https://news.detik.com/berita/d-3384849/mui-berita-hoax-bisa-mengancam-persatuan-dankesatuan-bangsa diakses pada 21 Maret 2018.

Effendy, Onong Uchjana. 2005. Ilmu Komunikasi: Teori dan Praktek. Bandung: Remaja Rosdakarya.

Gaus, A. 2013. Pemetaan Problem Radikalisme di SMU Negeri di 4 Daerah. Jakarta: MA'ARIF.

Hainun, Rusnita. 2014 "Pembentukan Karakter Siswa di Sekolah: Studi Kasus Pembelajaran Pendidikan Kewarganegaraan di SMA Negeri 4 Kota Bengkulu”.Disertasi.Program Pascasarjana UIN Sunan Kalijaga Yogyakarta. 
Hardjana, Agus M. 2003. Komunikasi Intrapersonal \& Komunikasi Interpersonal. Yogyakarta: Kanisius.

Hayadin. 2013. Tragedi Kecolongan Rohis: Keterlibatan Alumni Rohis SMKN Anggrek pada Aksi Radikalisme. Jurnal Al-Qalam.

Imania. 2012. Pengaruh Keaktifan Berorganisasi Kerohanian Islam (Rohis) Terhadap Kemandirian Belajar Siswa di Sekolah Menengah Atas Negeri 2 Salatiga Tahun Pelajaran 2012-2013. Salatiga: Jurusan Tarbiyah Prodi Pendidikan Agama Islam STAIN.

Ismmail, Faisal. 2014. Dinamika Kerukunan Antarumat Beragama. Bandung: PT Remaja Rosdakarya.

Kartawinata, Ade Makmur. 1999. Persatuan dan Kesatuan Bangsa: Suatu renungan Pembentukan Indonesia Merdeka Ke Arah Kebudayaan Kebangsaan. Bandung: Primaco Akademika.

Kartodirdjo, Sartono. 1999. Pembangunan Bangsa: Etos Nasionalisme dan Negara Kesatuan. Yogyakarta: Kanisius.

Khamdan, M. 2016. Pengembangan Nasionalisme Keagamaan Sebagai Strategi Penanganan Potensi Radikalisme Islam Transnasional. Jurnal Addin.

Membangun Budaya Damai melalui Pendidikan Agama. http://blasemarang.kemenag.go.id diakses pada 19 Maret 2018.

Mulyana, Deddy. 2007. Ilmu Komunikasi Suatu Pengantar. Bandung: Remaja Rosdakarya.

Najib Kailani. 2011. Kepanikan Moral dan Dakwah Islam Populer,Jurnal Analisis Vol. XI No. 1.

Noer, A., Tambak, S., Rahman, H. 2017. Upaya Ekstrakurikuler Kerohanian Islam (ROHIS) dalam Meningkatkan Sikap Keberagamaan Siswa di SMK Ibnu Taimiyah Pekanbaru. Jurnal AlThariqah.

Peraturan Menteri Agama No. 16 Tahun 2010 tentang Pengelolaan Pendidikan Agama Pada Sekolah.

Ridwan, N. K. 2012. Pancasila dan Deradikalisasi Berbasis Agama. Jurnal Pendidikan Islam.

Salim, Hairus HS, Najib Kailani dan Nikmal Azekiyah. 2011. Politik Ruang Publik Sekolah: Negosiasi dan Kontestasi di SMUN Yogyakarta. Yogyakarta: Monograf CRCS UGM. 
Soegondo, Sari. 2016. Kementerian Agama Kukuhkan Visi dan Kembangkan Strategi Peningkatan Kualitas Pendidikan Islamdi Indonesia. ACDP dan Kementerian Agama.

Sugiyarto. 2012. Tantangan Terhadap Eksistensi Negara Bangsa Indonesia dan Pemaknaan Kembali Nasionalisme. Jurnal Humanika.

Sugiyono. 2012. Metode Penelitian Kuantitatif, Kualitatif dan R\&D. Bandung: Alfabeta.

Wahid Foundation. 2016. Potensi Radikalisme di Kalangan Aktivis Rohani Islam di Sekolah-sekolah Negeri. Jakarta.

Wajidi, Farid. 2011. "Kaum Muda dan Pluralisme Kewargaan” dalam Zainal Abidin Bagir dkk. Pluralisme Kewargaan: Arah Baru Politik Keragaman di Indonesia. Jakarta: CRCS-Mizan.

West, Richad dan Lynn H. Turner. 2010. Introducing Communication Theory. New York: McGraw-Hill. 